\title{
The Importance of Obligate Anaerobes and the Streptococcus anginosus Group in Pulmonary Abscess: A Clone Library Analysis Using Bronchoalveolar Lavage Fluid
}

\author{
Hiroshi Mukae ${ }^{a, d}$ Shingo Noguchi ${ }^{a, c}$ Keisuke Naito ${ }^{a}$ Toshinori Kawanami ${ }^{a}$ \\ Kei Yamasaki ${ }^{a}$ Kazumasa Fukuda ${ }^{b}$ Kentaro Akata ${ }^{a}$ Yuichi Fukuda $^{d}$ \\ Takashi Kido $^{a}$ Hiroshi Ishimoto ${ }^{a}$ d Noriho Sakamoto ${ }^{d}$ Hatsumi Taniguchi ${ }^{b}$ \\ Kazuhiro Yatera ${ }^{\mathrm{a}}$ \\ Departments of ${ }^{\mathrm{a}}$ Respiratory Medicine and ${ }^{\mathrm{b}}$ Microbiology, University of Occupational and Environmental \\ Health, and ${ }^{c}$ Department of Respiratory Medicine, Wakamatsu Hospital of the University of Occupational and \\ Environmental Health, Kitakyushu, and ${ }^{\mathrm{d}}$ Department of Respiratory Medicine, Unit of Translational Medicine, \\ Nagasaki University Graduate School of Biomedical Sciences, Nagasaki, Japan
}

\section{Key Words}

Lung abscess · Obligate anaerobes · Streptococcus anginosus group $\cdot 16 \mathrm{~S}$ ribosomal RNA $\cdot$ Bronchoalveolar lavage fluid · Fusobacterium spp.

\footnotetext{
Abstract

Background: Appropriate antibiotic use reduces the mortality of patients with lung abscess; however, $40-60 \%$ of the bacterial etiologies in these patients have remained unknown with the culture methods. Obligate anaerobes and the Streptococcus anginosus group are common pathogens in lung abscess, but a precise evaluation of these bacteria by ordinary culture methods seems to be difficult due to upper respiratory tract contamination. Objectives: The aim of this study was to assess the microbiota of lung abscess by bronchoalveolar lavage fluid (BALF) using the molecular method in comparison to culture methods. Methods: BALF samples obtained from the affected lesions and sputum samples of
}

59 patients with lung abscess were evaluated. The microbiota in BALF was analyzed according to the molecular method using the $16 \mathrm{~S}$ ribosomal RNA gene. Results: Fifty-six of the 59 BALF samples were positive in polymerase chain reaction analysis. Fusobacterium spp. (23.7\%) were most frequently detected, followed by the $S$. anginosus group $(15.3 \%)$, as the predominant phylotypes. Obligate anaerobes were detected in $42.4 \%$ of the BALF specimens as the predominant phylotypes, whereas the detection rate of obligate anaerobes was $13.6 \%$ by culture methods using BALF. In addition, the detection rate among those patients in whom the phylotype of obligate anaerobes was detected in $>5 \%$ of the lung microbiota according to the molecular method was $86.5 \%$ in the 'mixed-bacterial' infection group. Conclusions: The findings by the molecular method suggest that obligate anaerobes play important roles in the pathogenesis of lung abscess and provide additional bacterial information regarding conventional culture methods.

(c) 2016 S. Karger AG, Basel

\section{KARGER}

E-Mail karger@karger.com www.karger.com/res
C 2016 S. Karger AG, Basel

$0025-7931 / 16 / 0922-0080 \$ 39.50 / 0$
Kazuhiro Yatera, MD, $\mathrm{PhD}$

Department of Respiratory Medicine

University of Occupational and Environmental Health

1-1 Iseigaoka, Yahatanishiku, Kitakyushu, Fukuoka 807-8555 (Japan)

E-Mail yatera@med.uoeh-u.ac.jp 


\section{Introduction}

Lung abscess is a microbial infection defined as a circumscribed collection of pus in the lung parenchyma, leading to cavity formation and/or an air-fluid level within the cavity [1]. Appropriate antibiotic use for the treatment of lung abscess has contributed to a decrease in mortality [2], which ranges from 2.4 to $20 \%$ [1, 3-5]. A precise understanding of the bacterial etiology of lung abscess is important for proper antibiotic selection and duration of treatment.

Obligate anaerobes and streptococci, which may often occur due to aspiration of oropharyngeal specimens [6], are common, while other facultative bacteria are less common, as bacteria causative of lung abscess [4]; 26$80 \%$ of lung abscesses are caused by obligate anaerobes $[2,4,7,8]$.

Sputum cultures are generally not useful in the diagnosis of causative pathogens of lung abscess, due to unavoidable bacterial contamination in the upper respiratory tract, although this method is commonly used. On the other hand, bacteriological assessments of lung abscess using bronchoscopic examination, transthoracic needle aspiration, and surgically resected tissues have also been reported in some studies $[2-4,6,8]$. The precise detection of obligate anaerobes requires anaerobic culture conditions and an appropriate duration of culture, and routine aerobic bacterial culturing may not identify the true pathogens in the lung [3]. Indeed, previous reports have shown that in $37.3-64.3 \%$ of patients, the lung abscesses have an unknown etiology $[1,2,4]$, and a recent report from Taiwan showed that Klebsiella pneumoniae was the most important pathogen in lung abscess [4]. Thus, the bacterial etiology of lung abscess is still not fully understood.

Molecular biological methods, particularly sequencebased approaches using the $16 \mathrm{~S}$ ribosomal RNA (rRNA) gene, have recently been used as culture-independent methods for identifying causative bacteria in respiratory infections $[9,10]$. We previously reported the microbiota in patients with community-acquired pneumonia (CAP) [11], healthcare-associated pneumonia (HCAP) [12] using bronchoalveolar lavage fluid (BALF) specimens, and bacterial pleurisy using pleural effusion [13] according to a bacterial 16S rRNA gene sequencing clone library analysis. The method we used has beneficial effects in that it can estimate bacterial species because of the relatively longer length of sequences (approx. $600 \mathrm{bp}$ ) compared to next-generation sequencing. Using this method, important roles for obligate anaerobic bacteria and oral strep- tococci in lower respiratory tract infections have been demonstrated among patients with CAP [11], HCAP [12], and bacterial pleuritis [13] when compared to ordinary culture methods.

In this study, we investigate the lung microbiota in BALF specimens from lung abscess patients using both the clone library method and conventional culture methods.

\section{Patients and Methods}

\section{Study Population}

This study was a prospective multicenter trial targeting patients with lung abscess on whom a bronchoscopic examination was performed. This study was conducted at the University of Occupational and Environmental Health, Japan, as well as in affiliated community hospitals between October 2013 and April 2015. This study was approved by the Human and Animal Ethics Review Committee of the University of Occupational and Environmental Health, Japan (No. 09-118, UMIN000011840). All patients provided their written informed consent prior to enrollment in the study. Clinical information and laboratory and radiological findings were collected.

\section{Definitions}

Lung abscess was diagnosed when the following three criteria were fulfilled: (1) the presence of new areas of infiltrations with a cavity or low-density area within the infiltrates on chest radiographs and/or CT; (2) new clinical findings including at least two of the following: a fever, sputum production, coughing, chest pain, and leukocytosis (peripheral white blood cell count $\geq 10,000 / \mu \mathrm{l}$ ), and (3) exclusion of other causes.

\section{Sample Collection}

Bronchofiberscopy was performed, avoiding any contamination from the upper respiratory tract if possible, and BALF was obtained from abscess lesions of the affected lung identified on chest radiographs and/or chest CT using $40 \mathrm{ml}$ of sterile saline as previously described $[11,12]$. Sputum specimens were also evaluated in patients with sputum production.

Total Bacterial Cell Count and Cell Lysis Efficiency Analysis

Total bacterial cell counts and the efficiency of cell lysis were evaluated using epifluorescence microscopy as previously described [11-13].

\section{Microbiological Evaluation Using Conventional Culture} Methods

Bacterial culture of the BALF and sputum specimens was performed using a semiquantitative method $[11,12]$. All positive culture results were described as microbial identification [12].

DNA Extraction and Polymerase Chain Reaction, Clone Library Construction, and Nucleotide Sequence Determination

DNA samples were extracted from the BALF, and 16S rRNA gene amplifications were performed with the universal primer sets (E341F and E907R) using a polymerase chain reaction (PCR) ther- 
Fig. 1. Patient inclusion and exclusion flow diagram. CRP $=$ C-reactive protein.

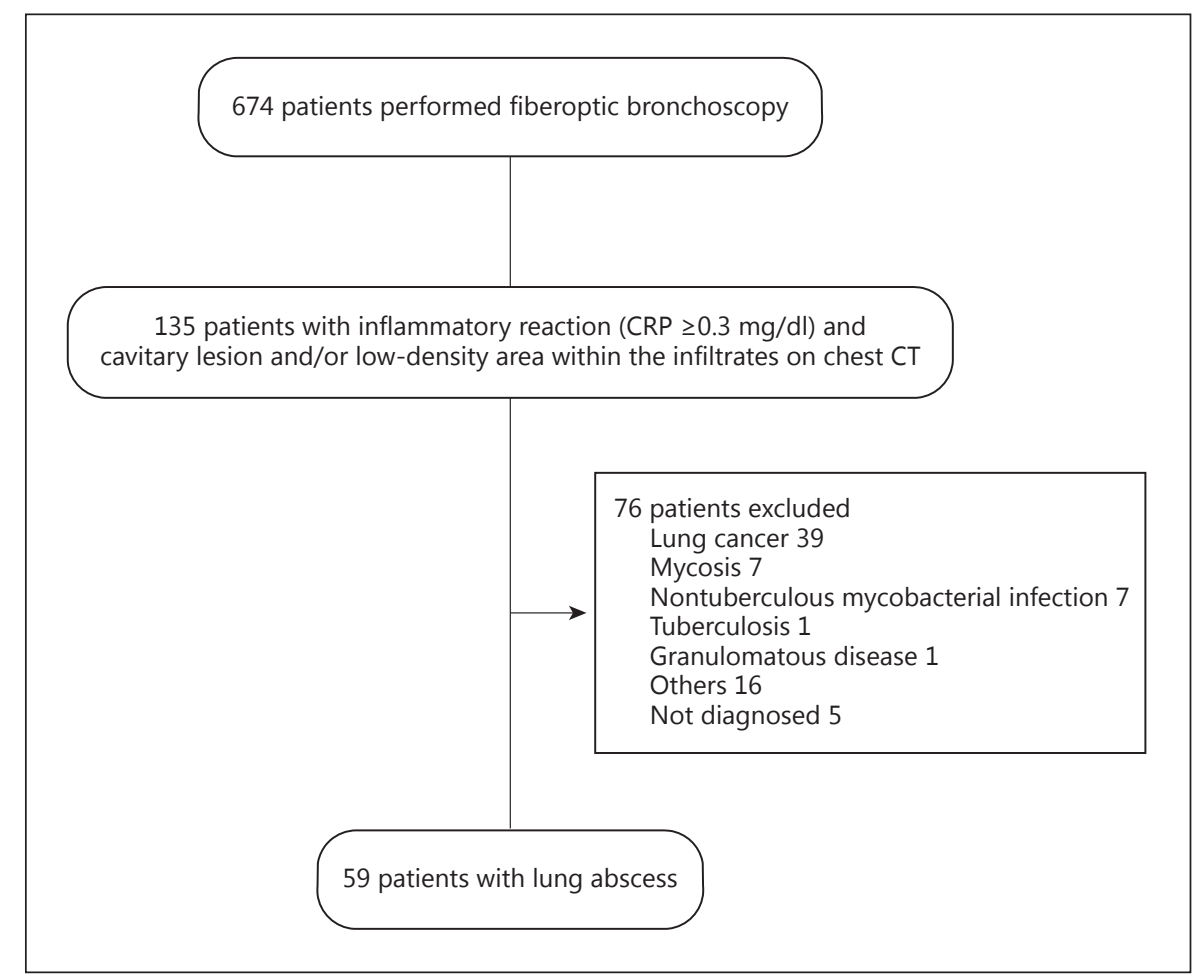

mocycler (GeneAmp PCR system 9700; Applied Biosystems, Foster City, Calif., USA) [11, 12]. Cloning of the PCR products was performed using the TOPO TA Cloning Kit (Invitrogen, Carlsbad, Calif., USA). The nucleic acid sequences of 96 randomly selected clones in each clone library were determined using a 3130xl Genetic Analyzer (Applied Biosystems).

\section{Homology Search}

Highly accurate sequences selected by Phred quality values were trimmed from the primer and vector regions, and only the sequences with good quality were used for the analysis. The detected sequences were compared with an in-house database containing the 16S rRNA gene sequences of 5,870 type strains using the basic local alignment search tool algorithm. The 16S rRNA gene sequences of type strains were obtained from the DNA Data Bank of Japan (http://www.ddbj.nig.ac.jp/) and the Ribosomal Database Project (http://rdp.cme.msu.edu/) [11-13].

Definition of Mono- or Mixed-Bacterial Infection Groups

Patients belonged to the 'mono-bacterial' infection group when the most predominant phylotype comprised over $80 \%$ of the detected bacterial phylotypes in each BALF sample using the clone library method, while patients who did not fall into this category were assigned to the 'mixed-bacterial' infection group $[11,12]$.

\section{Statistical Analysis}

Fisher's exact test for tables $(2 \times 2)$ and the Mann-Whitney test were used as appropriate. All analyses were performed using the SPSS software package (version 19). $\mathrm{p}<0.05$ was considered to be statistically significant.

\section{Results}

\section{Patient Characteristics}

During the study period, 135 of 674 outpatients who underwent bronchofiberscopy were enrolled, and eventually 59 patients with lung abscess were evaluated (fig. 1). The baseline characteristics of these 59 patients are presented in table 1 . The average age was $68.3 \pm 10.6$ years, the ratio of males was $76.3 \%$, and $66.1 \%$ of the patients had 1 or more comorbid diseases. The average time from symptom onset to hospital visit was $13.6 \pm 14.8$ days, and cavity formation was found in $50.8 \%$ of the patients.

\section{Total Bacterial Cell Count}

Positive PCR results detecting the $16 \mathrm{~S}$ rRNA gene in the BALF specimens were found in $94.9 \%$ of the patients using the clone library method; the total bacterial cell counts ranged from $1.2 \times 10^{4}$ to $8.9 \times 10^{8} \mathrm{cells} / \mathrm{ml}$ (median: $1.0 \times 10^{6}$ ), whereas all those in patients with negative PCR results were $<10^{4}$ cells $/ \mathrm{ml}$. The cell lysis efficiency was maintained at $\geq 80 \%$ in all specimens.

\section{Results of Culture Methods Using Sputum and BALF}

The conventional culture methods identified bacteria in 66.1 and $42.4 \%$ of the patients using BALF and sputum 
Table 1. Clinical and laboratory parameters of the 59 patients with lung abscess

\begin{tabular}{|c|c|}
\hline Age, years & $68.3 \pm 10.6$ \\
\hline Gender (male/female) & $45 / 14$ \\
\hline BMI & $20.5 \pm 3.9$ \\
\hline \multicolumn{2}{|l|}{ Comorbidities } \\
\hline Neoplastic diseases & $5(8.5)$ \\
\hline Cerebrovascular diseases & $4(6.8)$ \\
\hline Chronic pulmonary diseases & $15(25.4)$ \\
\hline Cardiac diseases & $9(15.3)$ \\
\hline Liver diseases & $3(5.1)$ \\
\hline Renal diseases & $2(3.4)$ \\
\hline Diabetes mellitus & $15(25.4)$ \\
\hline Collagen vascular diseases & $4(6.8)$ \\
\hline No comorbidity & $20(33.9)$ \\
\hline Smoking history & $40(67.8)$ \\
\hline Current & $19(32.2)$ \\
\hline Duration of symptoms, days & $13.6 \pm 14.8$ \\
\hline \multicolumn{2}{|l|}{ Symptoms } \\
\hline Fever & $36(61.0)$ \\
\hline Cough & $32(54.2)$ \\
\hline Sputum & $28(47.5)$ \\
\hline Chest pain & $11(18.6)$ \\
\hline Previous antibiotic treatment & $19(32.2)$ \\
\hline \multicolumn{2}{|l|}{ Laboratory findings } \\
\hline White blood cell counts, $/ \mu \mathrm{l}$ & $12,500 \pm 8,499$ \\
\hline C-reactive protein, $\mathrm{mg} / \mathrm{dl}$ & $11.9 \pm 8.6$ \\
\hline Albumin, g/dl & $3.0 \pm 0.5$ \\
\hline $\mathrm{BUN} \geq 21 \mathrm{mg} / \mathrm{dl}$ & $4(6.8)$ \\
\hline Glucose $\geq 250 \mathrm{mg} / \mathrm{dl}$ & $3(5.1)$ \\
\hline Hct $<30 \%$ & $13(22.0)$ \\
\hline \multicolumn{2}{|l|}{ Radiographic findings } \\
\hline Right upper lobe & $12(20.3)$ \\
\hline Right middle lobe & $13(22.0)$ \\
\hline Right lower lobe & $15(25.4)$ \\
\hline Left upper lobe & $4(6.8)$ \\
\hline Left lower lobe & $11(18.6)$ \\
\hline Bilateral & $4(6.8)$ \\
\hline Cavity formation & $30(50.8)$ \\
\hline Pleural effusion & $9(15.3)$ \\
\hline PSI score & $88.5 \pm 30.6$ \\
\hline In-hospital mortality & $3(5.1)$ \\
\hline
\end{tabular}

Data are presented as $\mathrm{n}(\%)$ or means $\pm \mathrm{SD} . \mathrm{BMI}=$ Body mass index; PSI = pneumonia severity index.

specimens, respectively (table 2). BALF culture demonstrated that streptococci (except for Streptococcus pneumoniae and the S. anginosus group) (27.1\%) were most frequently cultured, followed by Staphylococcus aureus (16.9\%) and Staphylococcus spp. (except S. aureus) (10.2\%). Obligate anaerobes were cultured in $13.6 \%$ of the patients using BALF specimens. Sputum culture demonstrated that streptococci (except for S. pneumoniae and the S. anginosus group) (25.4\%) were most frequently cultured, followed by Corynebacterium spp. $(20.3 \%)$ and S. aureus (13.6\%). In $16(27.1 \%)$ and 14 (23.7\%) of the 59 patients, 2 or more bacterial species were isolated from BALF and sputum specimens, respectively. The average numbers of bacteria in these patients were 3.3 and 4.0 using BALF and sputum specimens, respectively.

\section{Predominant Bacterial Phylotypes Using the Clone Library Method}

Fusobacterium spp. (23.7\%) were most frequently detected as the predominant phylotype, followed by the $S$. anginosus group (15.3\%), streptococci (except for $S$. pneumoniae and the S. anginosus group) (11.9\%), Parvimonas spp. (6.8\%), and S. pneumoniae (5.1\%) (table 2). The details for all patients obtained by the molecular method are shown in online supplementary table S1 (for all online suppl. material, see www.karger.com/ doi/10.1159/000447976). Using the clone library method, obligate anaerobic phylotypes were detected in 25 patients $(42.4 \%)$ as the predominant phylotypes, and the $16 \mathrm{~S}$ rRNA gene was amplified in 18 (90\%) of 20 patients in whom no bacteria were identified in the BALF cultures [obligate anaerobes ( $\mathrm{n}=7$; Fusobacterium spp., Parvimonas spp., and Porphyromonas spp.), the S. anginosus group $(\mathrm{n}=4)$, and streptococci (except for S. pneumoniae and the $S$. anginosus group; $\mathrm{n}=3$ )].

\section{Evaluation of the Proportion of Microbiota according to the Clone Library Method}

Among the 56 (94.9\%) of the 59 patients in whom bacterial phylotypes were detected by the clone library method, $19(33.9 \%)$ and 37 patients (66.1\%) were categorized into the 'mono-bacterial' infection and the 'mixed-bacterial' infection groups, respectively. In the mono-bacterial infection group, the $S$. anginosus group was most frequently detected in 6 of the 19 patients $(31.6 \%)$ as the predominant phylotype, whereas obligate anaerobes ( $>5 \%$ of the bacterial flora in each sample) were detected in 32 of the 37 patients $(86.5 \%)$ in the mixed-bacterial infection group (fig. 2). Conversely, $S$. anginosus group phylotypes ( $>5 \%$ of the bacterial flora in each sample) were detected in only 6 of the 37 patients (16.2\%). The ratio of mono-bacterial infection among patients in whom the $S$. anginosus group was detected as the predominant phylotype was significantly higher than that among patients with obligate anaerobes (table 3). 
Table 2. The results of the conventional culture method and the predominant phylotypes according to the molecular method in 59 patients

\begin{tabular}{|c|c|c|c|}
\hline & \multicolumn{2}{|c|}{ Conventional culture method } & \multirow{2}{*}{$\begin{array}{l}\text { Clone library method } \\
\text { in BALF: predominant } \\
\text { phylotype }\end{array}$} \\
\hline & sputum & BALF & \\
\hline Gram-positive pathogens & $47(79.7)$ & $48(81.4)$ & $22(37.3)$ \\
\hline S. pneumoniae & $4(6.8)$ & $3(5.1)$ & $3(5.1)$ \\
\hline S. aureus & $8(13.6)$ & $10(16.9)$ & $2(3.4)$ \\
\hline Methicillin-susceptible S. aureus & $3(5.1)$ & $3(5.1)$ & \\
\hline Methicillin-resistant S. aureus & $1(1.7)$ & $4(6.8)$ & \\
\hline Unknown $^{\mathrm{a}}$ & $4(6.8)$ & $3(5.1)$ & \\
\hline Staphylococcus spp. (except for S. aureus) & $6(10.2)$ & $6(10.2)$ & \\
\hline S. anginosus group & $2(3.4)$ & $4(6.8)$ & $9(15.3)$ \\
\hline \multicolumn{4}{|l|}{ Streptococcus spp. (except for S. pneumoniae } \\
\hline Granulicatella spp. & & & $1(1.7)$ \\
\hline Corynebacterium spp. & $12(20.3)$ & $9(15.3)$ & \\
\hline Bacillus spp. & & $1(1.7)$ & \\
\hline Gram-negative pathogens & $20(33.9)$ & $18(30.5)$ & $9(15.3)$ \\
\hline Haemophilus influenzae & $2(3.4)$ & $2(3.4)$ & $2(3.4)$ \\
\hline Haemophilus spp. (except for H. influenzae) & $4(6.8)$ & $5(8.5)$ & \\
\hline Moraxella catarrhalis & $1(1.7)$ & & $1(1.7)$ \\
\hline Klebsiella spp. & $2(3.4)$ & $3(5.1)$ & $2(3.4)$ \\
\hline Pseudomonas aeruginosa & $1(1.7)$ & $1(1.7)$ & $2(3.4)$ \\
\hline Escherichia coli & $1(1.7)$ & & \\
\hline Enterobacter spp. & $2(3.4)$ & $1(1.7)$ & $1(1.7)$ \\
\hline Acinetobacter spp. & $1(1.7)$ & & \\
\hline Neisseria spp. & $6(10.2)$ & $5(8.5)$ & $1(1.7)$ \\
\hline Raoultella spp. & & $1(1.7)$ & \\
\hline Anaerobic pathogens & & $8(13.6)$ & $25(42.4)$ \\
\hline Fusobacterium spp. & & & $14(23.7)$ \\
\hline Parvimonas spp. & & $3(5.1)$ & $4(6.8)$ \\
\hline Prevotella spp. & & $3(5.1)$ & $2(3.4)$ \\
\hline Porphyromonas spp. & & & $2(3.4)$ \\
\hline Veillonella spp. & & $1(1.7)$ & \\
\hline Actinomyces spp. & & $1(1.7)$ & \\
\hline Dethiosulfovibrio spp. & & & $1(1.7)$ \\
\hline Eubacterium spp. & & & $1(1.7)$ \\
\hline Propionibacterium spp. & & & $1(1.7)$ \\
\hline Oral bacteria & & $1(1.7)$ & \\
\hline Mixed infection & $14(23.7)$ & $16(27.1)$ & $37(62.7)$ \\
\hline Aerobes only & $14(23.7)$ & $10(16.9)$ & \\
\hline Anaerobes only & $0(0.0)$ & $0(0.0)$ & \\
\hline Mixture of aerobic and anaerobic pathogens & $0(0.0)$ & $6(10.2)$ & \\
\hline No pathogen identified & $34(57.6)$ & $20(33.9)$ & $3(5.1)$ \\
\hline
\end{tabular}




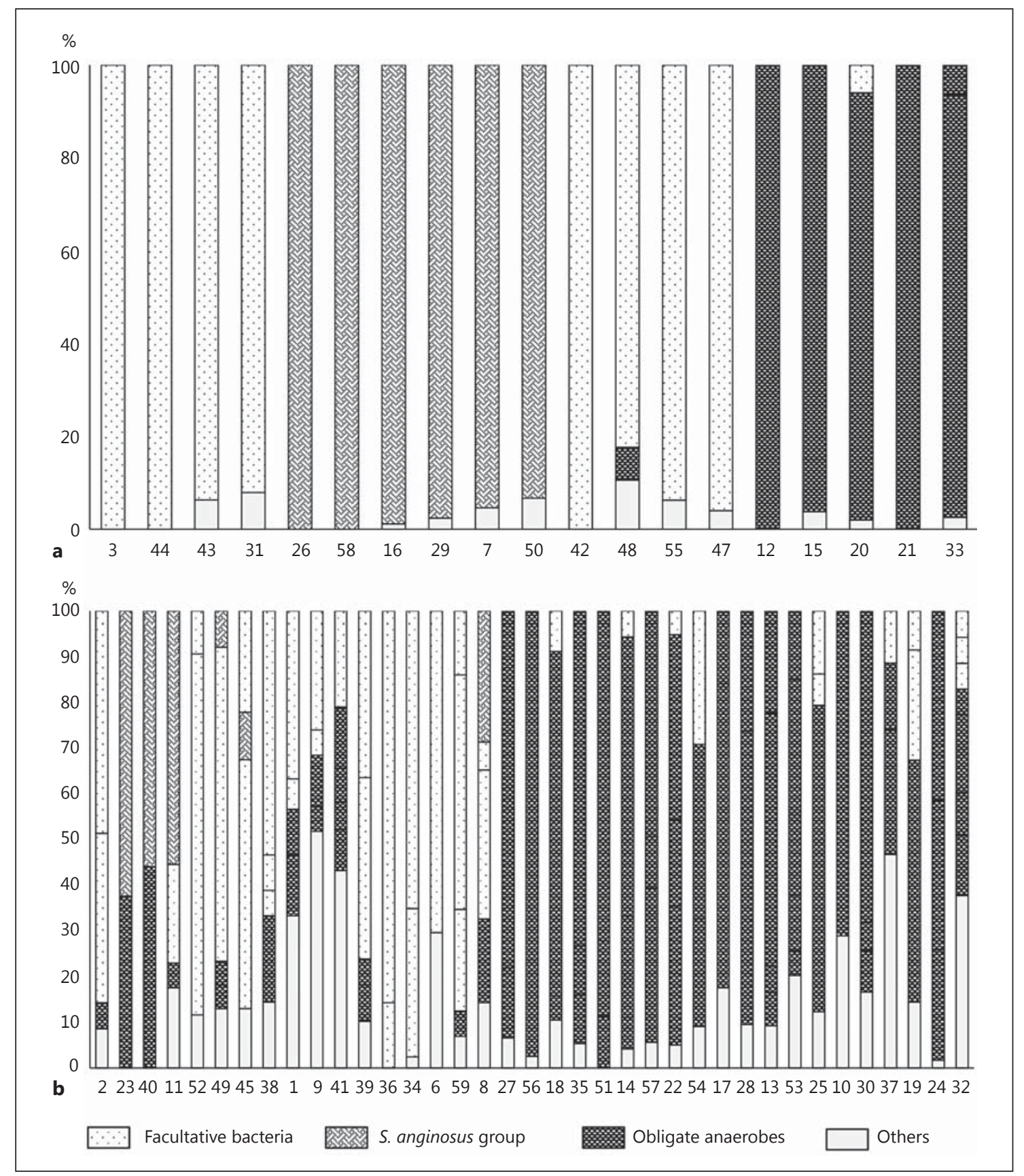

Fig. 2. Proportion of microbiota in the mono-bacterial and mixed-bacterial infection groups as determined by the clone library method. a Mono-bacterial group. b Mixed-bacterial group.

Comparison of the Backgrounds of Patients in Whom Facultative Bacteria, the S. anginosus Group, and Obligate Anaerobes Were Detected as the Predominant Phylotypes

The clinical and laboratory parameters of the patients in whom facultative bacteria, the $S$. anginosus group, and obligate anaerobes were detected as the predominant phylotypes are shown in table 3. Patients with the $S$. anginosus group were significantly older than those with obligate anaerobes, and cerebrovascular diseases were significantly more frequently observed in patients with the $S$. anginosus group than in patients with facultative bac- 
Table 3. Clinical characteristics of the patient groups with facultative bacteria, the S. anginosus group, and obligate anaerobes

\begin{tabular}{|c|c|c|c|c|}
\hline & $\begin{array}{l}\text { Facultative bacteria } \\
(\mathrm{n}=22)\end{array}$ & $\begin{array}{l}\text { S. anginosus group } \\
(\mathrm{n}=9)\end{array}$ & $\begin{array}{l}\text { Obligate anaerobes } \\
(\mathrm{n}=25)\end{array}$ & $\mathrm{p}$ value \\
\hline Age, years & $68.7 \pm 10.5$ & $76.0 \pm 6.8$ & $64.8 \pm 9.9$ & $\leq 0.05^{1}$ \\
\hline Males & $17(77.3)$ & $7(77.8)$ & $19(76.0)$ & n.s. \\
\hline BMI & $19.7 \pm 3.6$ & $21.2 \pm 5.9$ & $20.8 \pm 3.4$ & n.s. \\
\hline \multicolumn{4}{|l|}{ Comorbidities } & n.s. \\
\hline Neoplastic diseases & $5(22.7)$ & $0(0.0)$ & $0(0.0)$ & $\leq 0.05^{2}$ \\
\hline Cerebrovascular diseases & $0(0.0)$ & $3(33.3)$ & $1(4.0)$ & $\leq 0.05^{3}$ \\
\hline Chronic pulmonary diseases & $7(31.8)$ & $3(33.3)$ & $4(16.0)$ & n.s. \\
\hline Cardiac diseases & $5(22.7)$ & $2(22.2)$ & $2(8.0)$ & n.s. \\
\hline Liver diseases & $0(0.0)$ & $0(0.0)$ & $3(12.0)$ & n.s. \\
\hline Renal diseases & $1(4.5)$ & $0(0.0)$ & $1(4.0)$ & n.s. \\
\hline Diabetes mellitus & $3(13.6)$ & $1(11.1)$ & $11(44.0)$ & $\leq 0.05^{2}$ \\
\hline Collagen vascular diseases & $2(9.1)$ & $0(0.0)$ & $2(8.0)$ & n.s. \\
\hline No comorbidity & $9(40.9)$ & $3(33.3)$ & $6(24.0)$ & n.s. \\
\hline Smoking history & $14(63.6)$ & $8(88.8)$ & $18(72.0)$ & n.s. \\
\hline Current & $4(18.2)$ & $2(22.2)$ & $13(52.0)$ & $\leq 0.05^{2}$ \\
\hline Duration of symptoms, days & $9.0 \pm 10.4$ & $15.2 \pm 9.1$ & $17.2 \pm 19.2$ & $\leq 0.05^{4}$ \\
\hline \multicolumn{4}{|l|}{ Symptoms } & n.s. \\
\hline Fever & $13(59.1)$ & $4(44.4)$ & $17(68.0)$ & n.s. \\
\hline Cough & $11(50.0)$ & $5(55.6)$ & $14(56.0)$ & n.s. \\
\hline Sputum & $9(40.9)$ & $5(55.6)$ & $14(56.0)$ & n.s. \\
\hline Chest pain & $3(13.6)$ & $2(22.2)$ & $5(20.0)$ & n.s. \\
\hline Preantibiotic treatment & $6(27.3)$ & $4(44.4)$ & $6(24.0)$ & n.s. \\
\hline \multicolumn{5}{|l|}{ Laboratory findings } \\
\hline White blood cell count, $/ \mu \mathrm{l}$ & $10,596 \pm 7,237$ & $17,602 \pm 15,672$ & $12,922 \pm 5,176$ & n.s. \\
\hline C-reactive protein, $\mathrm{mg} / \mathrm{dl}$ & $12.8 \pm 8.2$ & $16.6 \pm 11.9$ & $9.3 \pm 7.4$ & n.s. \\
\hline Albumin, g/dl & $2.9 \pm 0.58$ & $2.8 \pm 0.5$ & $3.0 \pm 0.5$ & n.s. \\
\hline $\mathrm{BUN} \geq 21 \mathrm{mg} / \mathrm{dl}$ & $4(18.2)$ & $0(0.0)$ & $0(0.0)$ & $\leq 0.05^{2}$ \\
\hline Glucose $\geq 250 \mathrm{mg} / \mathrm{dl}$ & $0(0.0)$ & $1(25.0)$ & $2(13.3)$ & n.s. \\
\hline Hct $<30 \%$ & $9(40.9)$ & $1(11.1)$ & $3(12.0)$ & $\leq 0.05^{2}$ \\
\hline \multicolumn{5}{|l|}{ Radiographic findings } \\
\hline Right upper lobe & $6(27.3)$ & $1(11.1)$ & $4(16.0)$ & n.s. \\
\hline Right middle lobe & $2(9.1)$ & $3(33.3)$ & $7(28.0)$ & n.s. \\
\hline Right lower lobe & $7(31.8)$ & $2(22.2)$ & $5(20.0)$ & n.s. \\
\hline Left upper lobe & $1(4.5)$ & $0(0.0)$ & $3(12.0)$ & n.s. \\
\hline Left lower lobe & $4(18.2)$ & $3(33.3)$ & $3(12.0)$ & n.s. \\
\hline Bilateral & $3(13.6)$ & $0(0.0)$ & $1(4.0)$ & n.s. \\
\hline Cavity formation & $13(59.1)$ & $3(33.3)$ & $11(44.0)$ & n.s. \\
\hline Pleural effusion & $6(27.3)$ & $1(11.1)$ & $2(8.0)$ & n.s. \\
\hline Mono-bacterial group & $8(36.4)$ & $6(66.6)$ & $5(20.0)$ & $\leq 0.05^{1}$ \\
\hline PSI score & $104 \pm 38$ & $89 \pm 20$ & $75 \pm 17$ & $\leq 0.05^{5}$ \\
\hline In hospital mortality & $3(13.6)$ & $0(0.0)$ & $0(0.0)$ & n.s. \\
\hline
\end{tabular}

Data are presented as $\mathrm{n}(\%)$ or means $\pm \mathrm{SD}$. BMI $=$ Body mass index; PSI = pneumonia severity index; $\mathrm{n} . \mathrm{s} .=$ not significant.

${ }^{1}$ Statistically significant difference between the S. anginosus and the obligate anaerobes groups.

${ }^{2}$ Statistically significant difference between the obligate anaerobes and facultative bacteria groups.

${ }^{3}$ Statistically significant difference between the S. anginosus and facultative bacteria/obligate anaerobes groups.

${ }^{4}$ Statistically significant difference between the facultative bacteria and S. anginosus groups.

${ }^{5}$ Statistically significant difference between the obligate anaerobes and facultative bacteria/S. anginosus groups. 
teria or obligate anaerobes. However, patients with diabetes mellitus (DM) as a comorbidity were significantly more often observed to have obligate anaerobes isolated than facultative bacteria. Abnormal findings of blood urea nitrogen $(\mathrm{BUN} ; \geq 21 \mathrm{mg} / \mathrm{dl}$ ) and hematocrit (Hct; $<30 \%$ ) were significantly more frequently observed in patients with facultative bacteria than in patients with obligate anaerobes. Peripheral white blood cell counts, serum levels of C-reactive protein, and radiological findings were not significantly different between the three groups.

\section{Discussion}

In this study, the clone library method showed the utility of the molecular method in detecting obligate anaerobes and streptococci, suggesting that anaerobes play important roles in the pathogenesis of lung abscess. Additionally, we suggest that the $S$. anginosus group is especially important in elderly patients with comorbid cerebrovascular diseases.

Obligate anaerobes and the $S$. anginosus group are well known to be causative pathogens of lung abscess, whereas the etiology is unknown in $37.3-64.3 \%$ of lung abscess patients $[1,2,4]$. It was also reported that $K$. pneumoniae was an important pathogen in Taiwanese lung abscess patients [4]. Thus, the etiology of lung abscess has remained unclear. The molecular method we used has the potential merits that no conditional preparation is required and bacterial species are estimated. On the other hand, our method has the problem of how to reduce the influence of upper respiratory tract contamination in the evaluation of the bacterial flora of lower respiratory infections. Although the bronchoscopic evaluation we used in the present study unavoidably had the potential to introduce upper respiratory tract contamination, we had previously reported that PCRs for detecting the $16 \mathrm{~S}$ rRNA gene in BALF specimens were negative for all patients $(n=30)$ with interstitial pneumonia (noninfectious causes) and that a total bacterial cell count of $>10^{4}$ cells $/ \mathrm{ml}$ is a useful criterion for indicating bacterial infection in BALF [11]. Thus, the present method using bronchofiberscopy is very useful for evaluating obligate anaerobes and oral bacteria [11-13]. In addition, the molecular method could evaluate the bacterial flora in $94.9 \%$ of the BALF specimens from patients with lung abscess in this study - as compared to $66.1 \%$ using the culture methods. Therefore, we believe that our results provide valuable information for understanding the etiology of patients with lung abscess.

Obligate Anaerobes and the S. anginosus

Group in Pulmonary Abscess
Our data demonstrated that obligate anaerobes were most frequently detected as the predominant phylotypes, and these rates were obviously high in comparison to the rates of anaerobes in our previous reports on CAP (15.6\%) and HCAP (9.8\%) [11, 12]. Especially, Fusobacterium spp. accounted for half of the obligate anaerobes detected, and all of the 14 cases of Fusobacterium spp. were determined to be F. nucleatum, which has been reported to be a major anaerobic bacterium in lung abscess patients [5]. Thus, we reconfirmed the clinical importance of these bacterial species in lung abscess patients.

Members of the $S$. anginosus group are facultative anaerobic pathogens that colonize the upper airways and tend to form pus due to their unique characteristics [1416]. In addition to obligate anaerobes, the $S$. anginosus group is common in the etiology of patients with lung abscess [2,17-19], and it was the second most common bacterial phylotype detected in the present study. The detection rate of these bacteria was less than half of the cases in cultures in this study, and the prevalence of these oral bacteria might be underestimated in real-world clinical settings. Similarly to a former report, which described a link between the aspiration of oral flora and lung abscess development [20], our results also indicate the important and close relationship between oral bacterial flora and lung abscess. Therefore, physicians should be more aware of the $S$. anginosus group as primary pathogens of lung abscess.

Mixed infections have been recognized as being important in the pathogenesis of lung abscess, and have been reported in $21-50 \%$ of cases $[2,4,6]$. Moreover, obligate anaerobes and streptococci are common in lung abscess patients with mixed infections $[5,6,21]$. Obligate anaerobe phylotypes ( $>5 \%$ of the microbiota in the BALF specimens) were detected in $86.5 \%$ of the mixed-bacterial group using the molecular method, and obligate anaerobes had previously been detected in $67.7 \%$ of CAP [11] and $46.0 \%$ of HCAP [12] patients, respectively. Our results by the molecular method may thus indicate that obligate anaerobes play a greater role in patients with lung abscess than in pneumonia patients [11, 12].

In the present study, similarly to previous observations $[1,4,5]$, lung abscess was predominantly observed in adult males with comorbidities, patients with a history of unconsciousness, smoking, and long duration from the onset of symptoms to the hospital visit, especially among those patients with lung abscess caused by obligate anaerobes (table 1). No differences were observed in the duration from the onset of symptoms to the hospital visit between patients with lung abscess caused by aerobes and 
those with lung abscess caused by obligate anaerobes, although significant differences were found between patients with lung abscess caused by the $S$. anginosus group and those with lung abscess caused by aerobic bacteria. As complications in lung abscess patients, DM is one of the well-known risk factors for lung abscess [2], and the incidence of morbidities in DM patients with periodontal diseases is approximately two or three times that in healthy individuals $[22,23]$. In comparison with aerobes, obligate anaerobes were significantly more frequently detected in patients with DM as the predominant phylotypes in this study, indicating that obligate anaerobes were some of the main bacteria in patients with lung abscess complicated with DM, although dental conditions were not evaluated in this study. In addition, abnormal findings for BUN and Hct were significantly more frequently observed in patients with aerobes than in those with obligate anaerobes as the most predominant phylotypes in the present study. Patients with lung abscess complicated with anemia showed significantly higher mortality rates in addition to basic physical conditions, including underlying diseases [1], and elevated BUN and decreased Hct values were risk factors for severe pneumonia. Physicians should, therefore, also be aware of these abnormal laboratory findings in lung abscess patients.

There are several limitations associated with this study [11-13]. First, although we believe that our method using BALF is a useful tool for evaluating obligate anaerobes and/or oral streptococci, the influence of possible contamination of the upper respiratory tract should be considered. Second, because it took several days to obtain the final results with the clone library method we used, we could not apply the bacterial information obtained by the molecular method to the selection of antibiotics during this study. Furthermore, we mainly used antimicrobial agents that were effective against obligate anaerobes in the present study; thus, we could not analyze the influence in the selection of antibiotic treatment according to the results of molecular analysis. Third, approximately 100 clones per library were analyzed, suggesting that bacterial $16 \mathrm{~S}$ rRNA gene sequences present at small fractions $(<1 \%$ of each sample) may be undetectable.

In conclusion, obligate anaerobes and the $S$. anginosus group were more often detected by use of the molecular method than by conventional culture methods in patients with lung abscess. These results suggest that physicians should consider the importance of these bacteria as pathogens of lung abscess and also take this information into consideration when selecting antibiotics that are effective against obligate anaerobes.

\section{Acknowledgements}

The authors thank Drs. Chiharu Yoshii, Hideto Obata, Yusuke Taura, Yukiko Kawanami, Yugo Yoshida, Takeshi Orihashi, Chinatsu Nishida, Naoyuki Inoue, Takaaki Ogoshi, Yu Suzuki, Susumu Tokuyama, and Keishi Oda for collecting the samples, and Ms. Yoshiko Yamazaki, Kumiko Matsuyama, and Michiyo Taguchi for their valuable assistance.

\section{Financial Disclosure and Conflicts of Interest}

This study was partially supported by a High Altitude Research Grant from the University of Occupational and Environmental Health, Japan, a Ministry of Education, Science, Sports and Culture Grant-in-Aid for Scientific Research [(C), 23591173, 2011; (C), 26461172, 2014] and a Ministry of Education, Science, Sports and Culture Grant-in-Aid for Young Scientists [(B), 24790828, 2012]. All authors declare to have no conflicts of interest.

\section{References}

-1 Hirshberg B, Sklair-Levi M, Nir-Paz R, BenSira L, Krivoruk V, Kramer MR: Factors predicting mortality of patients with lung abscess. Chest 1999;115:746-750.

$>2$ Takayanagi N, Kagiyama N, Ishiguro $\mathrm{T}$, Tokunaga D, Sugita Y: Etiology and outcome of community-acquired lung abscess. Respiration 2010;80:98-105.

$>3$ Moreira Jda S, Camargo Jde J, Felicetti JC, Goldenfun PR, Moreira AL, Porto Nda S: Lung abscess: analysis of 252 consecutive cases diagnosed between 1968 and 2004 (in English, Portuguese). J Bras Pneumol 2006;32: 136-143.
-4 Wang JL, Chen KY, Fang CT, Hsueh PR, Yang PC, Chang SC: Changing bacteriology of adult community-acquired lung abscess in Taiwan: Klebsiella pneumoniae versus anaerobes. Clin Infect Dis 2005;40:915-922.

5 Bartlett JG: Anaerobic bacterial infection of the lung. Anaerobe 2012;18:235-239.

6 Peña Griñan N, Muñoz Lucena F, Vargas Romero J, Alfageme Michavila I, Umbria Dominguez S, Florez Alia C: Yield of percutaneous needle lung aspiration in lung abscess. Chest 1990;97:69-74.

$>7$ Bartlett JG: The role of anaerobic bacteria in lung abscess. Clin Infect Dis 2005;40:923925 .
$>8$ Mori T, Ebe T, Takahashi M, Isonuma H, Ikemoto H, Oguri T: Lung abscess: analysis of 66 cases from 1979 to 1991. Intern Med 1993;32: 278-284.

9 Bahrani-Mougeot FK, Paster BJ, Coleman S, Barbuto S, Brennan MT, Noll J, Kennedy T, Fox PC, Lockhart PB: Molecular analysis of oral and respiratory bacterial species associated with ventilator-associated pneumonia. J Clin Microbiol 2007;45:1588-1593. 
10 Lu W, Yu J, Ai Q, Liu D, Song C, Li L: Increased constituent ratios of Klebsiella sp., Acinetobacter sp., and Streptococcus sp. and a decrease in microflora diversity may be indicators of ventilator-associated pneumonia: a prospective study in the respiratory tracts of neonates. PLoS One 2014;9:e87504.

11 Yamasaki K, Kawanami T, Yatera K, Fukuda K, Noguchi S, Nagata S, Nishida C, Kido T, Ishimoto $\mathrm{H}$, Taniguchi $\mathrm{H}$, Mukae H: Significance of anaerobes and oral bacteria in community-acquired pneumonia. PLoS One 2013;8:e63103.

12 Noguchi S, Mukae H, Kawanami T, Yamasaki K, Fukuda K, Akata K, Ishimoto H, Taniguchi $\mathrm{H}$, Yatera K: Bacteriological assessment of healthcare-associated pneumonia using a clone library analysis. PLoS One 2015; 10: e0124697.

13 Kawanami T, Fukuda K, Yatera K, Kido M, Mukae $\mathrm{H}$, Taniguchi H: A higher significance of anaerobes: the clone library analysis of bacterial pleurisy. Chest 2011;139:600-608.
14 Siegman-Igra Y, Azmon Y, Schwartz D: Milleri group streptococcus - a stepchild in the viridans family. Eur J Clin Microbiol Infect Dis 2012;31:2453-2459.

15 Sunwoo BY, Miller WT: Streptococcus anginosus infections: crossing tissue planes. Chest 2014;146:e121-e125.

16 Noguchi S, Yatera K, Kawanami T, Yamasaki K, Naito K, Akata K, Shimabukuro I, Ishimoto $\mathrm{H}$, Yoshii C, Mukae $\mathrm{H}$ : The clinical features of respiratory infections caused by the Streptococcus anginosus group. BMC Pulm Med 2015; 15:133.

17 Shinzato T, Saito A: The Streptococcus milleri group as a cause of pulmonary infections. Clin Infect Dis 1995;21(suppl 3):S238-S243.

18 Jerng JS, Hsueh PR, Teng LJ, Lee LN, Yang PC, Luh KT: Empyema thoracis and lung abscess caused by viridans streptococci. Am J Respir Crit Care Med 1997;156:1508-1514.
9 Ahmed RA, Marrie TJ, Huang JQ: Thoracic empyema in patients with community-acquired pneumonia. Am J Med 2006;119:877883.

20 Henriquez AH, Mendoza J, Gonzalez PC: Quantitative culture of bronchoalveolar lavage from patients with anaerobic lung abscesses. J Infect Dis 1991;164:414-417.

21 Hammond JM, Potgieter PD, Hanslo D, Scott $\mathrm{H}$, Roditi $\mathrm{D}$ : The etiology and antimicrobial susceptibility patterns of microorganisms in acute community-acquired lung abscess. Chest 1995;108:937-941.

22 Chávarry NG, Vettore MV, Sansone C, Sheiham A: The relationship between diabetes mellitus and destructive periodontal disease: a meta-analysis. Oral Health Prev Dent 2009; 7:107-127.

23 Mealey BL, Oates TW; American Academy of Periodontology: Diabetes mellitus and periodontal diseases. J Periodontol 2006;77:12891303. 